\title{
Actionable Knowledge As A Service (AKAAS): Leveraging big data analytics in cloud computing environments
}

\author{
Audrey Depeige ${ }^{1 *}$ and Dimitri Doyencourt ${ }^{2}$
}

\author{
* Correspondence: \\ audrey.depe@bumail.net \\ ${ }^{1}$ Telecom Ecole de Management, 9 \\ rue Charles Fourier, 91000 Evry, \\ France \\ Full list of author information is \\ available at the end of the article
}

\begin{abstract}
Knowledge-as-a service is an emerging research trend that constitutes a promising path for organizations aiming to achieve better customer support and decision-making across a wide range of content providers. However, only few studies have explored how traditional knowledge management processes and practices are challenged and evolve in relation to social and technological transformation stemming from the new age of cloud-computing environments. This research paper attempts to answer this gap by introducing a new framework for the management of knowledge in the cloud.

The objective of this study is twofold. First, it aims to develop a knowledge-based decision framework using recent knowledge-as-as-service paradigms for creating, retrieving and reusing technical knowledge in cloud environments. Second, and in relation to this view, the current state of data analysis (business intelligence, big data analytics) is assessed in light of cloud computing environments and the simultaneous emergence of new knowledge management paradigms. An overview of cloud computing challenges is given as well as a representation of supporting knowledge management processes, followed by the description of related applications of the AKAAS (Actionable Knowledge As A Service) operating framework.

The first part of the research develops upon literature on Knowledge Management Systems (KMS) frameworks. The second part of this study examines and assesses the nature of data and analytics required to provide on-demand delivery of knowledge in the cloud. Finally, the third part of the paper explores practical applications of the framework to guide the development of knowledge management processes and practices towards internal and external users adoption. We conclude by suggesting future research directions, including case studies examining differential knowledge cloud-based designs.
\end{abstract}

Keywords: Cloud computing; Knowledge management; Knowledge as a service; Data analytics; Business intelligence; User-centered practices

\section{Introduction}

Scholarly research predicted that the cloud-computing environment, thanks to its ondemand access orientation, would enable in the upcoming years [1] to integrate and deliver knowledge on an open platform as a "kind of cloud service". The idea of selling knowledge as a service is not new [2]. It appeared with the rise of consulting firms 
since early in the 60's so as to ensure the competitiveness of organizations. However, there is still an important lack of studies examining knowledge services and practices in cloud computing environment, as well as precise models depicting the framework and how it can be served by analytics to facilitate knowledge management in a service approach. The first part of this paper thus reviews the nature and role of existing knowledge management systems as well as their potential evolution in relation with the emergence cloud computing services.

\section{From Knowledge Management Systemes (KMS) approaches to Actionable Knowledge As A Service (AKAAS)}

The field of knowledge management has flourished over the last decades, simultaneously creating new businesses for software developers, vendors, consultants, as well as generating cycles of "hypes and disappointments" [3], remaining a disputed field, however paradoxically deployed over a large spectrum of business operations. Several schools of thoughts have paved the way towards the development of knowledge management (KM) applications that could help capture people knowledge (tacit knowledge) and formalize it under an explicit form for later reuse.

\section{The era of enterprise Knowledge Management Systems}

Previous research emphasizes that, knowledge, despite being codified into Information Technology (IT) solutions, first originates from individuals, whom are using the same IT systems, and thus, through their action, contribute to add value to knowledge management [2]. Moving forward, it appears that existing KM systems (KMS) aim first at centralizing the knowledge available across organization, built around a central channel to access knowledge assets. Consequently KMS tend to appear as a standalone information solution [4], which often neglects tacit dimensions of knowledge as well as the importance of new technological paradigms such as the emergence of social networks. What is more, organizations often fail to put in place the required efforts to develop, implement and sustain such KM systems [5], partly because employees are reticent to fully adopt the system. This lack of adoption is mostly due to a lack of guidance and preparation to effectively share their knowledge through such systems, whereas the majority of these systems promised to help organizations with several differentiation areas such as problem solving, decision making, business intelligence and monitoring [3].

Practically speaking, well-established KM systems were arranged under different layers: the front end part that deals with internal and external users, and acts as a provider of knowledge services, and the back-end that mostly authors knowledge and contributes to document and refresh knowledge base systems. Such KMS are therefore mainly focusing on knowledge storage and retrieval capabilities. In sum, KM typically consisted of the knowledge base of the organization, supported by adequate knowledge management processes (adding, removing, modifying content in the knowledge base), while the content is mostly accessed via search queries [3]. In contrast to this structural approach, research showcased that ICT consumption behaviors [6] are the main factors that will drive the cloud-computing environment, not architectures. In other words, and beyond technologies, cloud computing developments are tightly interlinked with new ways of connecting, engaging in and sustaining business, while simultaneously transforming and changing ways to access, consume and use Information Systems (IS) 
and Information Technology (IT) in daily life. Such challenges and issues are reflected in the next section.

\section{Issues and challenges in cloud computing environments}

Cloud computing aims to make accessible resources "which an organization can harness, anywhere in the world via internet" [6], in a context where business practices focusing on transforming ubiquitous data appears as critical [7] in order to leverage operational efficiency. In contrast to this, previous platforms used to gather together content that was then globally distributed - without necessarily being adapted to specific business contexts or customer needs. Such approaches are oriented towards a push-only delivery method, thus reflecting the rigidity of workflows and philosophy underlying enterprise conventional KM systems: those fail to deliver the information in the right manner and to make it searchable so that the most relevant responses are presented to the user [5]. In contrast to this view, we argue that cloud computing environments require challenging traditional information paradigms and taking into account social and technological evolutions that dominant current work practices to elaborate adequate knowledge discovery paradigms.

The need for knowledge that is discoverable "on-demand" is part of such recent evolutions and greatly impacts the nature, structure, and security parameters of data necessary to provide contextualized and real time analytics [8]. This is fully aligned with the essence of cloud-computing paradigm, which derives from the idea that users shall be able to access on-demand to any application, wherever the users are located in the world [7]. In particular, Khoshnevis and Rabeifar's research [4] indicates that the deployment of KM in cloud environments involve to store knowledge "in great sizes for learning and inference requirements for computational capacity" and illustrate this evolution by instances of content publication that are addressed to a specific group of users (for instance, publishing a problem to problem-solvers). The traditional model of accessing knowledge therefore needs to shift to deliver knowledge resources that are consumed whenever the users needs them (not being time bound), in some cases paid for by the consumer, thus forming a utilitarian-based information system" [6]. This main aspect of KM in cloud-computing environment (shifting from a global push to a full service approach) is detailed in the next section.

\section{Towards new knowledge management modalities: rethinking opportunities through AKAAS}

Cloud computing paradigms are become increasingly popular, due to decreases in terms of costs, efforts and resources to deploy solutions in line with customer needs. However, there remains some concerns regarding performance (outages), reliability and data security risks [5] while some aspects governance and usability can represent a challenge in terms of successful adoption [9], explaining that the adoption has been slow in comparison with the initial enthusiasm [10]. Delic and Riley envisioned that, cloud-computing environment were first an opportunity for massive collaboration between people, while the future of cloud-computing may involve the operation of intelligent virtual objects and devices that would collaborate with people [3]. These evolutions would translate into consequent impacts in the field of knowledge management, as the possibilities in terms of availability, scalability, reliability, elasticity and flexibility given by the cloud symbolize 
opportunities to develop and put in place new ways of delivering knowledge services to customers. Therefore, main aspects of knowledge management in the cloud are oriented towards "new found knowledge, new ways of fostering collaboration and new learning paradigms" [11] thus outpacing numerous of traditional KM systems and knowledge repositories. In fact, cloud computing materializes "the idea of "everything as a Service" [4].

Cloud computing is actually based on the idea of providing instantly accessible, modularly and highly customizable solutions, among which knowledge that is needed by the customer to perform daily work activities. We therefore suggest that knowledge management in the cloud involves that the retrieval and enrichment of knowledge content is fully driven by consumers' needs and requirements, whatever the channels traditionally used to deliver such contents. Pursuing this perspective, we argue that more than the volume of produced content being "king" - numbers reflecting the amounts of published content have dominated the selling value of knowledge platforms for a long time - consumers needing this knowledge and their interaction behaviors are truly key to understand in order to adapt the definition and deployment of KM projects. Following this view, the first and recent attempts to describe knowledge as a service lacked of precision and suggested " a kind of service that facilitates the interoperations among members in a knowledge network" [12]. Other previous attempts to conceptualize knowledge as a service consisted in deploying a "digital version of a knowledge worker as a service oriented program that answers knowledge-related queries via a knowledge server" where knowledge as a service can be conceived as "an on-demand knowledge store, which is capable of searching, analyzing and restructuring its knowledge resources" [13].

Besides the traditionally storage and tools oriented knowledge systems, we suggest that knowledge applications, in order to become service oriented, need to be replaced by KM programs that place knowledge consumers at the center and therefore seek to expand towards the offerings and availability of on-demand knowledge through a variety of channels. In other words, knowledge management in cloud computing environment seeks to enable available knowledge assets to be gathered, and customized according to dedicated consumer contexts and needs, even if such dimension may only exist for a certain period of time [6]. This reflects the fact that workers need to access knowledge that is accurate, in the right amount (neither too little nor too much) [4] and that is also actionable in order to induce valuable results from its use.

Additionally, there is a need for a dynamic solution delivery, which should be based upon context aware services [14]. This is because the efficiency, with which organizations acquire the necessary knowledge to act upon and so, achieve their business goals, constitutes the primary source of competitive advantage [13]. Ju and Shen [15] emphasized that the development of knowledge services contributes to the development of workers as well as to the improvement of their productivity. These evolutions of traditional KM approaches (capitalization) towards services, and more specifically towards an "Actionable Knowledge As A Service" (AKAAS) approach, are represented in Fig. 1 below.

The above figure highlights that the understanding of specific consumers needs as well as of their interactional behaviors is key in the success of KM principles deployment in the cloud (AKAAS), thus requiring to understand how content consumers use the knowledge provided in their own context (relevancy) and attempt to configure the knowledge resources available to them (customization). This illustrates the fact that knowledge management needs to evolve from a model that was oriented towards a global knowledge 


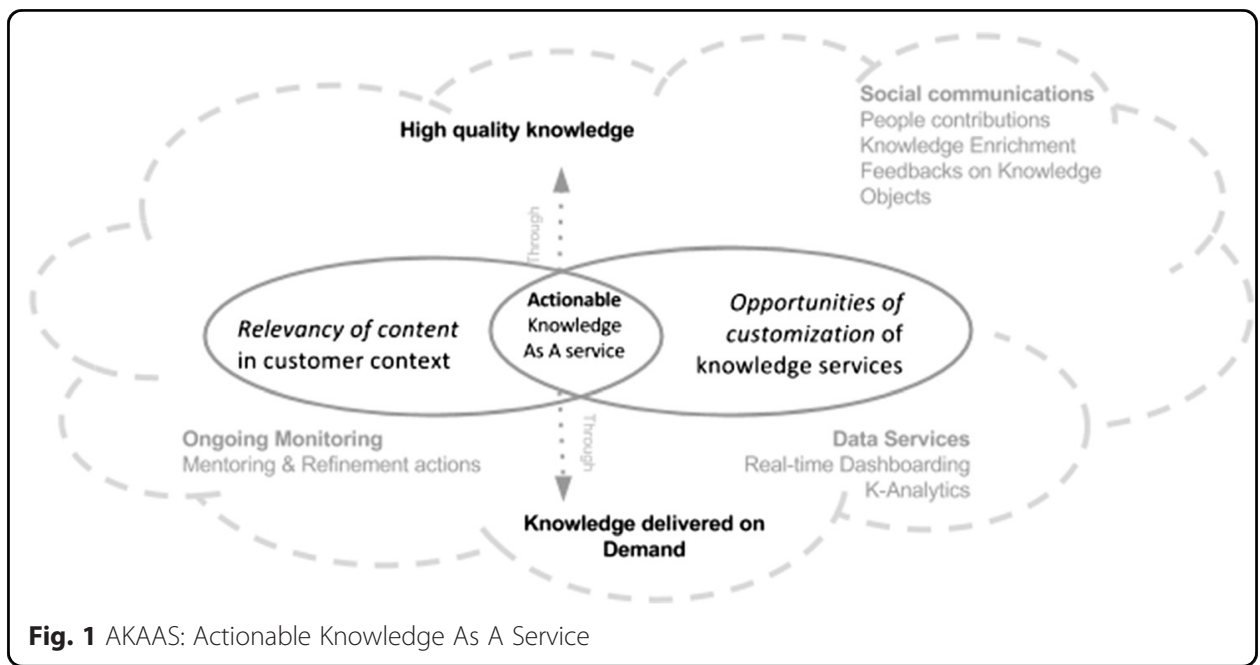

delivery; to an alternative model that emphasizes a personalized knowledge acquisition by users [1]. These new dimensions, seeking to ensure the actionnability of knowledge delivered to customers, are clearly aspects for which specific data-based inputs are required. These propositions are supporting the systematic identification of how consumers retrieve, interact with content, share it to others and contribute to enrich it through different medium. This last orientation is consistent with cloud computing paradigms, which are expected to enable firm to execute data transactions along their value added activities [7]. The role of data and analytics in supporting the AKAAS approach in cloud environments is introduced in the next part of the paper.

\section{On-demand delivery of knowledge: Knowledge Analytics seek predictive drift}

An important success factor of the AKAAS approach is whether the knowledge discovered by users can meet business requirements of the same users [16], which constitutes the basis for decision-making and value creation outcome. Traditionally, business intelligence (BI) reporting, supported KM systems by giving an overview on and helping to determine whether there were general issues with the content process steps (authoring, review, publication, obsolescence, etc....), outlining that knowledge management and BI need to "be considered together as necessarily integrated and mutually critical components in the management of intellectual capital" [17].

\section{The enhancement of Bls universe through contextualized knowledge analytics (K-analytics)}

BI has often been associated with technologies aiming to gather and analyze data. More recently, business intelligence has been conceived as a set of methodologies, techniques and tools that were mainly utilized in order to compute analytics on top of business data and enable its representation under forms that enabled decision-makers to establish diagnostics and prediction related to their business [8]. As a first analysis stage, BI universe thus helps understand where there are main pin-point in organizational knowledge management processes, which however involves a more systematic analysis of potential factors that shall be included in the analysis of the identified issue (this may 
include descriptive data such as the count of number of views, value of ratings and evaluation, average age of the content, etc.). Therefore, and to gain insights on user needs, the data extracted from BI universe still requires an amount of time and crossanalysis effort that may become difficult seeing the amount of data available and various representation possibilities given by descriptive statistics. Traditional BI activities therefore involved a number of steps to perform on the data available in the universe, including the selection filtering, transformation, creation, integration and formatting of data" [16], this despite initially advocating the possibility to speed up decision-making processes and lead execution in real time [18].

Besides, previous research has argued that the analysis of business processes cannot only rely on quantitative data provided under BI softwares [17]. Current technological evolutions such as the semantic web technology and solutions enabling a better visualization of data and information are interesting to consider in the context of knowledge services, for instance to move from actual values of the knowledge objects (cleaned data) towards more predictive deliveries of knowledge, and, ultimately, computation capabilities that enable to generate real-time data and uncover relationship and patterns in interactions with data, which gives more insights about user dimensions and contexts, on the basis of their interactions with the content. This evolution of BI provided analytics towards contextualized Knowledge analytics is described in the Fig. 2 that follows.

More advanced methods to analyze data such as predictive modeling can be applied through different methods such as machine learning and are assessed against validity predictors, the results interpreted and evaluated as having the potential to drive the satisfaction of end users needs. In fact, it is essential for organizations such as customerfacing departments to have a real-time overview on the user's interactions with their product and feedbacks. Besides, time spent creating knowledge may contribute to heighten the cost of the review process and maintenance of the knowledge created. Due to such issues, organizations may introduce more systematic ways such as data mining techniques in order to identify customer needs in terms of knowledge, which

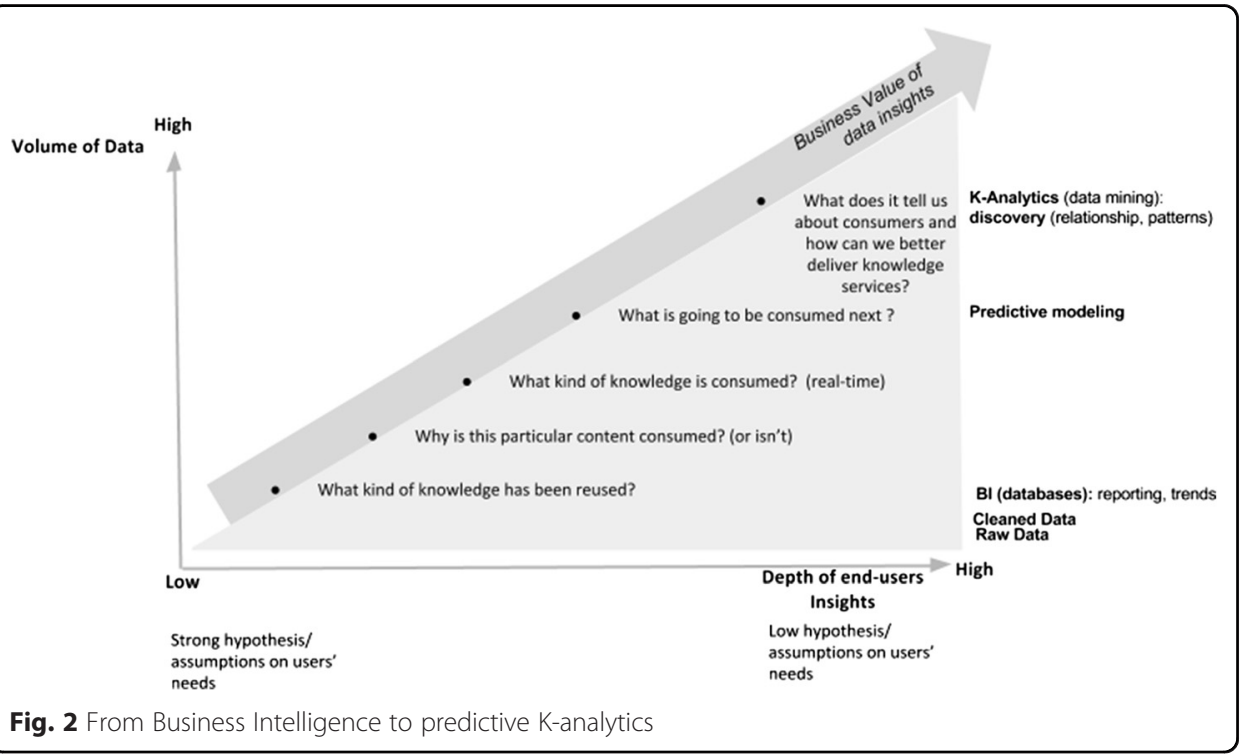


does not only depend on maintenance and case resolution but also on the ability to gain useful knowledge and make effective and informed decision in their context of use. For instance, a pilot study conducted by Dixon et al. [9] concluded that decision support in the cloud appears as feasible and leads the way to better decision-making. Following this view, it is argued that the combination of knowledge, technologies such as semantic and text mining techniques together with IT systems enable organizations to gain a new understanding, and experience of knowledge-related services [1]. Besides, it shall be noted that organizations may use different mining techniques to identify and gain insights on the same problems [16]. These include for instance modeling techniques as well as clustering techniques (leading to the identification of knowledge demands areas and knowledge gaps areas) that are critically needed for organizations to explore the data (once cleaned from potential inconsistencies) and its results into easily communicable formats.

\section{From Big Data to Real data: towards predictive realities}

Early research conducted in the field of data mining and knowledge discovery indicates that both fields still lack of an integrated and comprehensive approach [19]. In contrast to this view, we have seen in the previous part of this paper, that the implementation of additional analytics capabilities contributes to extend the use of BI technologies, making the combination between knowledge management and data highly beneficial for decision-makers and players involved in the delivery of knowledge services. Such applications include providing "real-time context-aware analytics related to various real-life objects selected by the users [8]. The K-analytics enable to compute users needs based on the demand of knowledge and so present to consumers the knowledge results and suggestions that are adapted to the context in which they use the product commercialized by the provider. In the above example, analytics appear as a valuable addition to BI features. For instance, one may look into and mine search logs to obtain knowledge and information on identifying user needs. In this case, text data mining or knowledgediscovery analytical methods (which refer to the extraction of non-trivial information and knowledge [17] from unstructured text, and its processing) enable providers to draw insights on those knowledge domains, which have a higher value and potential with users (due to an elevated demand rate, for instance). Along with this view, the extraction of patterns from important volumes of data aims to support decision-making [19] by enabling analysts to investigate and gain understanding on the phenomena underlying this data.

Features and use cases of knowledge analytics seek to benefit the end user by identifying key insights enabling the delivery of on-demand, in context, timely and relevant information [8]. It shall be noted that, satisfactory and tailored services can only be delivered under the condition that the nature of the information, the person that will reuse it or apply it, the circumstance under which it will be applied as well as the timing under which it will occur are known in advance [17]. In light of this argument, one possible implementation of more advanced analytics is therefore to enable content contributors and authors to autonomously create content by explicitly identifying the need for knowledge delivery and therefore refining (repackaging) or creating relevant knowledge objects. This is because traditional knowledge bases can never be fully exhaustive and thus unavoidably tend to reveal content gaps, which constitute a potential source of frustration for the user 
during the exploration and discovery of knowledge [20]. Consequently, it is expected that the idea of leveraging using big data insights to better manage and deliver knowledge services does not reside in a single benefit, rather increases the benefits for a number of knowledge services and underlying processes offered in cloud environment (e.g. identifying what users are interested in, which queries still need to be answered because the content of the knowledge base is incomplete, etc....).

In sum, the value addition of integration of knowledge management technologies and data analytics techniques resides in providing alternative scenarios and therefore a more complete view of decision-making problematic, contributing to measure "how well it promotes and enhances knowledge, and how well it improves the mental model(s) and understanding of the decision maker(s)" [17]. In line with this argument, the articulation between data analytics and AKAAS as the KM framework to manage knowledge in cloud computing contexts is described in the last part of the paper that follows.

\section{The influence of AKAAS and K-Analytics on KM processes and practices in cloud environments}

Cloud computing can be defined as "a modality, (...) for delivering a range of ICT services through software and virtual hardware provisioned by data centers owned and operated by cloud providers and/or end users) according to user demands and requirements and delivered remotely" [5]. Referring to that definition, it becomes possible for a number of ICT companies to provide knowledge services through different types of clouds (public, private, hybrid clouds): the knowledge delivered will then be consumed by organizations and end users that are clients of the providing organization.

\section{Cloud computing and the deployment of Knowledge Services}

Some of the first descriptions of knowledge clouds depicted such developments as collaborative and cooperating environment, with structure that enable to provide services to knowledge producers and consumers such as computing, networking and storage services [3], highlighting the shift from traditional infrastructure to more agile configurations such as stack applications. In line with this view, and when compared to traditional computing services, cloud computing offers tangibles benefits in terms of knowledge services delivery such as the continuous and personalized delivery of knowledge assets over the web, offering flexibility and scalability through a "pay-as-you-go" service orientation [5].

The deployment of knowledge as a service thus involves two primary aspects that are monitoring the knowledge pushed to the "market" (consumers) as well as the market itself so that the creation of new knowledge can be adequately aligned with the knowledge needs of customers. For that reason, it is suggested that the fast rise of cloudcomputing solutions has certain implication in terms of knowledge lifecycle, shall it be around the creation of knowledge, the sharing of knowledge to internal and external audiences, or its reusability to meet the needs of organization and beneficiaries of new KM services. Therefore, one could say that the cloud-computing paradigm becomes an application of competencies that benefit the end user [21]. The cloud infrastructure indeed delivers the potential of having a gigantic amount of devices that are inter-connected, fostering the emergence of brand new applications [3] stimulating the development and availability of innovative solutions and applications. In particular 
and to achieve this goal, the solution should be accessible from any kind of device or platform used by the consumer, in any location and at anytime, meaning that it is not at the client end that the information is processed, rather at the cloud side [11]. This leads us to suggest few examples of new KM services in cloud-computing contexts, which include the repurposing of content mined from social media (user interactions) and resources into support cases (processes at the services' provider side), which benefits both the organization (the impact on the process of case handling remains minimal) and customers who benefit from interactions on their preferred social channel. Examples of practical applications and implications of the AKAAS vision are provided in the next paragraph.

\section{Content Management in Operations: AKAAS applications}

Tsui et al. have illustrated implications of the cloud from a knowledge-oriented viewpoint [11]: value added of knowledge management in the clouds lies in nurturing widespread and ad-hoc collaboration, by embracing and connecting together knowledge contents for individual and group learning purposes, with the support of various tools. This view clearly places the individual at the center of the cloud offering, emphasizing on the dimension of personal and collective tackling of information. This contrast with established in-house knowledge delivery systems which lacked of agility in meeting changing consumer demands at most were mostly challenging and complex in terms of deployment and administration, while remaining un-adapted to meet changing needs of corporate end-users and executives [5]. One of the benefits of combining data analytics with the AKAAS framework lies in advanced KM applications, which, beyond creating/updating/ archiving content that is usually accessed through search features, enable to successfully fulfill expectations of current consumers as well as future users. In fact, one of the challenges of knowledge management in cloud computing, and more generally information search, retrieval, evaluation and organization lies in the degree of complexity and sophistication of search engines [11], since in cloud contexts those are not only expected to retrieve the information, but also to advise its relevance and trustworthiness. To support these requirements, we propose that knowledge analytics therefore appear as key for knowledge management processes, and in particular we suggest to assess how organizational and customer knowledge is capitalized or created, broadcasted (shared) and reused by content consumers. This is consistent with definitions viewing knowledge management as processes encompassing the creation, organization, sharing and use of tacit and explicit knowledge [4]. The Table 1 here below illustrates the previous argument.

The role of data collected and incorporated on the fly, in a way that is transparent for the user [20] appears as critical in a context where the volume of interactions between customers and organizations challenge their capacities of adopting scalable customer service models, and embed connection on online channels as part of their case handling. Following this view, and by leveraging customer interaction analytics, organizations will be able to reshape their support strategy and to rearrange interactions across any channels [5] that meet changing behaviors of end-users. Other actionable benefits include the assurance of quality and timely delivery of content through various channels. In line with this view, Rao and Lu suggest to take into account the requirements of the knowledge services, the knowledge service process [1] as well as the quality of the knowledge service. 
Table 1 An illustration of a possible application of AKAAS and Knowledge Analytics in the context of cloud customers

\begin{tabular}{|c|c|c|}
\hline Knowledge Processes & K-Analytics & Benefits \\
\hline \multirow[t]{3}{*}{$\begin{array}{l}\text { Capturing/Creating } \\
\text { Knowledge }\end{array}$} & $\begin{array}{l}\square \text { Search query/search logs data analysis } \\
\text { (text mining \& clustering) }\end{array}$ & $\begin{array}{l}\text { Identification of knowledge needs and } \\
\text { services requirements }\end{array}$ \\
\hline & $\begin{array}{l}\square \text { What has been created? for which } \\
\text { audience? }\end{array}$ & $\begin{array}{l}\text { 口 Mapping knowledge coverage: } \\
\text { dashboarding of available knowledge } \\
\text { (main domains \& associated targets) }\end{array}$ \\
\hline & $\begin{array}{l}\square \text { Knowledge created vs. knowledge } \\
\text { searched and retrieved }\end{array}$ & $\begin{array}{l}\square \text { Value delivered analysis } \\
\text { (offer vs. demand bells) }\end{array}$ \\
\hline \multirow[t]{3}{*}{$\begin{array}{l}\text { Broadcasting/ } \\
\text { Sharing Knowledge }\end{array}$} & $\begin{array}{l}\square \text { Measuring entry and exit points on } \\
\text { multiple channels }\end{array}$ & $\begin{array}{l}\square \text { Providing real-time knowledge delivery } \\
\text { through relevant channels }\end{array}$ \\
\hline & $\square$ Click-through rates \& interactions & $\begin{array}{l}\square \text { Assessing the accessibility of content } \\
\text { and potential issues to be addressed } \\
\text { (keywords, tagging, etc....) }\end{array}$ \\
\hline & & $\square$ Curating knowledge \\
\hline \multirow[t]{4}{*}{$\begin{array}{l}\text { Reusing/Refining } \\
\text { Knowledge }\end{array}$} & $\begin{array}{l}\square \text { Search query data (text mining } \\
\text { analytics) }\end{array}$ & $\begin{array}{l}\square \text { Discovery of consumption patterns \& } \\
\text { interaction with content }\end{array}$ \\
\hline & $\begin{array}{l}\square \text { Interestingness/ Consumed contents } \\
\text { trends visualization (demand focus) }\end{array}$ & $\begin{array}{l}\square \text { Predicting future knowledge to } \\
\text { be created }\end{array}$ \\
\hline & $\begin{array}{l}\square \text { Indicators of quality of the results (ratings, } \\
\text { numbers of sharing, recommendations, } \\
\text { etc....) }\end{array}$ & $\begin{array}{l}\square \text { Identifying and solving potential } \\
\text { issues with the knowledge offer } \\
\text { (duplicates, overlaps, } \\
\text { gaps, etc....) }\end{array}$ \\
\hline & $\square$ Enrichment or modification requests & $\begin{array}{l}\square \text { Identify axis to improve authoring } \\
\text { guidelines and review processes }\end{array}$ \\
\hline
\end{tabular}

Table 2 presents below a comparative example of the implementation of the use of knowledge-analytics by six of the leading cloud-based knowledge services providers (provider brands has been anonimized).

These implementation examples and the particular focus made on analytics enabling to analyze content relevance for users demonstrate that, it comes forward that analytics are of critical value to help accompany the evolution in time of users behaviors, by contributing to identify key aspects in the way they consume content and connect and share information with others. In that way, analytics may be used to increase the relevancy, quality and timeliness of knowledge that is capture, broadcasted and refined (enriched) in order to cover internal and external customer needs. What is more, K-analytics can also be used to enable information analysis so that cloud users learn, develop and reflect on their knowledge [11]. This is a preliminary step towards an evolution of text-based and multimedia-based content towards active content [3]. In line with this view, Preda et al. have developed a view of an active knowledge base [20] supported by relevant data, that dynamically federates knowledge resources, part of the knowledge being maintained locally and part of the knowledge being dynamically retrieved from the web, the combination of which is mapped on the fly onto a local knowledge base and thereby enables knowledge as a service. Following this perspective of an interactional relationship with content (pushed content vs. inter-active content), we suggest that social computing paradigms and emerging collaborative approaches (i.e. collective flagging or tagging of knowledge objects, for instance) are necessary to support developments in the knowledge management field which we expect will draw the basis of development of new KM ecosystems where people are at the center of collective intelligence and evolving firm capabilities. This dimension of an interconnection between people, knowledge and analytics is covered in the next section. 
Table 2 K-analytics in context of self-service/customer support \& services implementation

\begin{tabular}{|c|c|c|c|}
\hline & $\begin{array}{l}\text { Capturing/creating } \\
\text { Knowledge \&related } \\
\text { Analytics dimensions }\end{array}$ & $\begin{array}{l}\text { Broadcasting/retrieving } \\
\text { knowledge \& related } \\
\text { Analytics dimensions }\end{array}$ & $\begin{array}{l}\text { Reusing/refining } \\
\text { knowledge \& related } \\
\text { Analytics dimensions }\end{array}$ \\
\hline \multirow[t]{2}{*}{ Provider 1} & $\begin{array}{l}\text { Solution Activity by } \\
\text { Month by Author }\end{array}$ & $\begin{array}{l}\text { Adoption - includes } \\
\text { number of search and views } \\
\text { (searches vs. views within } \\
\text { last } 14 \text { days) }\end{array}$ & $\begin{array}{l}\text { Effectiveness - did the } \\
\text { knowledge solve the } \\
\text { issues? }\end{array}$ \\
\hline & & Average Session Length & $\begin{array}{l}\text { Utilization -percentage } \\
\text { of solutions accessed and } \\
\text { useful/new knowledge } \\
\text { utilization for solutions } \\
\text { created within the last } \\
\text { three months }\end{array}$ \\
\hline
\end{tabular}

Aging - freshness of the knowledge and reviews needed/Published solution edited in last 14 days

KCS - amount of solutions were flagged and fixed

\section{Provider 2 Size and usageSize:}

- number of online questions/number of online answers

- items in publishing center/amount of new and unhandled requests

Usage: number of answered requests/ number of answers added/number of answers deleted

Provider 3

\section{Visit duration Search logs:}

- keywords \& trends, answered (popular searches, what customers are really interested in) and list of unanswered questions (top unanswered questions)

Search results shown to the users

\section{Contextual search filter:}

Filter user queries by contextual answers (category,

location, etc....)

\section{Query Count (number of reported queries) \\ Query Pipeline}

Name of a search interface from which the search events are performed.

\section{Average Click Rank Over Time}

Advanced Query + Expression/Keyword

Group To which a user performing the search event belongs

Audience page

Click count and Manual Query count data in relation with users performing the search events.

Search Result title and ID

Content gaps: frequent searches with no results or no clicks

Has Clicks: last search event, at least one click in the search results list/Has Results: last
QA traffic chart

Number of liked answers (which questions are most satisfactory for customers)/ statistics of numbers of liked' and 'disliked' per each Q\&A

Most Escalated questions

- graphic visualization of a question's progress over time 
Table 2 K-analytics in context of self-service/customer support \& services implementation (Continued)

\begin{tabular}{|c|c|c|c|}
\hline & & $\begin{array}{l}\text { search event, query that returned } \\
\text { at least one result. }\end{array}$ & \\
\hline & & $\begin{array}{l}\text { Queries and Keywords pages: } \\
\text { most frequent queries and } \\
\text { keywords with the poorest } \\
\text { Relevance index based on Click } \\
\text { count and Average click rank }\end{array}$ & \\
\hline & & $\begin{array}{l}\text { Documents page documents } \\
\text { with the poorest rank based } \\
\text { on the Relevance index }\end{array}$ & \\
\hline & & $\begin{array}{l}\text { Search Cause: automatic and } \\
\text { manual refinements }\end{array}$ & \\
\hline \multirow[t]{12}{*}{ Provider 4} & $\begin{array}{l}\text { Knowledge Article } \\
\text { Version (KAV): } \\
\text { information about } \\
\text { individual translations, } \\
\text { such as their creation } \\
\text { dates, published channels, } \\
\text { and number of associated } \\
\text { cases. }\end{array}$ & $\begin{array}{l}\text { Knowledge Article Searches: } \\
\text { number of searches per day, } \\
\text { month, or year for each channel } \\
\text { and role }\end{array}$ & $\begin{array}{l}\text { Knowledge Article } \\
\text { Votes: number of votes } \\
\text { per day, month, or year } \\
\text { for each channel and } \\
\text { role. }\end{array}$ \\
\hline & $\begin{array}{l}\text { Case association count: } \\
\text { Number of cases } \\
\text { attached to the article }\end{array}$ & $\begin{array}{l}\text { Cumulative Count: total number } \\
\text { of article searches }\end{array}$ & $\begin{array}{l}\text { Knowledge Article } \\
\text { Views: number of views } \\
\text { per day, month, or year } \\
\text { for each channel and } \\
\text { role }\end{array}$ \\
\hline & & $\begin{array}{l}\text { Knowledge Keyword Search: } \\
\text { keywords users are looking for }\end{array}$ & $\begin{array}{l}\text { Score: Article's average } \\
\text { view rating. }\end{array}$ \\
\hline & $\begin{array}{l}\text { Archived By: User who } \\
\text { archived the article. }\end{array}$ & $\begin{array}{l}\text { Knowledge Search Activity: } \\
\text { number of searches per day, } \\
\text { month, or year for each channel } \\
\text { and language. }\end{array}$ & \\
\hline & & $\begin{array}{l}\text { - For each search: Date, ID } \\
\text { and title of the article that } \\
\text { was clicked }\end{array}$ & \\
\hline & & $\begin{array}{l}\text { - keywords users are looking, } \\
\text { average number of: }\end{array}$ & \\
\hline & & $\begin{array}{l}\text { Results: The number of search } \\
\text { results that were returned for the } \\
\text { search term. }\end{array}$ & \\
\hline & & $\begin{array}{l}\text { - Articles that appear in the search } \\
\text { results }\end{array}$ & \\
\hline & & $\begin{array}{l}\text { - For each article, average number } \\
\text { of: Click, Unique users who } \\
\text { clicked it }\end{array}$ & \\
\hline & & Average Click Rank: & \\
\hline & & $\begin{array}{l}\text { order in which the article } \\
\text { appeared in search results } \\
\text { when users clicked it }\end{array}$ & \\
\hline & & $\begin{array}{l}\text { Channel: channel that's applicable } \\
\text { to the article. }\end{array}$ & \\
\hline \multirow[t]{6}{*}{ Provider 5} & & Total queries overtime & Clicks per visitor average \\
\hline & & Number of Queries with clicks & Unique visitors \\
\hline & & Number of Queries without clicks & Visits/sessions \\
\hline & & Number of Queries with no results & \\
\hline & & Top queries & \\
\hline & & Top keywords & \\
\hline
\end{tabular}


Table 2 K-analytics in context of self-service/customer support \& services implementation (Continued)

\author{
Search relevance: \\ Click ranks over time \\ Queries without clicks over time \\ Details of queries with low \\ relevance \\ Details of keywords with low \\ relevance \\ Content gaps: \\ Click through ratio \\ Details of queries without results \\ Details of keywords without results
}

\title{
Up in the clouds: embracing boundless collaborative knowledge
}

Khoshnevis and Rabeifar have argued [4] that an important part of organizational knowledge is acquired externally to the company and therefore does not dwell from within the organization, rather is mostly developed from interaction with customers, partners, competitors and other market stakeholders. In line with this view, recent developments of technologies have enabled wide-scale collaborations and undeniable emergence of collective intelligence [3] towards new forms of knowledge management. It appears that the organization's KM initiatives can be supported and assisted by cloud computing and online social networking tools [5]. This contrast with past KM efforts, which were often hampered by a variety of issues such as technological and financial constraints. Additionally, usual database systems were suffering internal adoption issues, as outlined in the study of Sultan [5]: one of the reasons was that employees used to consider some of the information they were requested to share as essential to preserve their job, while others considered information logging into a centralized database as time consuming, and, finally, workers tend to prefer seeking information from peers rather than from an online knowledge-base system.

These cases highlights the need for cloud computing providers to incorporate or partner with social network solutions that can help address the behavioral issues encountered by corporations deploying traditional KM systems, in a context where cloud computing significantly contributes to decrease cost and technological obstacles, that constituted a heavyweight of numerous KM projects. In line with this view, first conceptualizations of knowledge as a service intended the paradigm as aiming for the development of collaborative networks and activities [12]. Despite initial performance issues, it is argued that cloud computing remains a compelling environment for the introduction of fine modularity in the delivery of knowledge services that go beyond existing Web 2.0 paradigms, at an attractive cost. In sum, cloud computing both offers organizations with more scalable and secure knowledge services, which take a more flexible and advantageous cost-wise, and also contribute to reduce the technical challenges of knowledge management initiatives [5]. Indeed, in the context of the cloud it becomes possible to manage and deliver knowledge to a specific groups of users (i.e. 
internal audiences, partners, or customers of a private cloud), notwithstanding that these audiences should be able to interconnect, overlay and share knowledge together [3]. In line with this proposition, Rao and Lu indicate that actionable knowledge that is created by workers, customers and partners forms a knowledge sharing platform [1], thereby suggesting that this new model provides more opportunities to discover and purchase the service or knowledge under different forms: either by search engines, online communities and networks, or consulting subject matter experts online.

In fact, and although corporations usually put an emphasis on the push approach of content and delivering knowledge through technologies, the importance of cloud computing and its modularization possibilities points out that the essence of KM in cloud computing environment mainly relies on the people dimension, thus consisting and succeeding in its ability to connect employees with each other and enable them to get answers at the right moment, while maintaining content actives when employees leave and continuously refining existing content through social interconnections [5]. The highest contribution to $\mathrm{KM}$ in cloud-computing environment therefore mostly comes from people (both organization's workers and product end-users), who, supported by adequate collaborative tools and platforms, are invited to contribute and enrich the knowledge shared with peers and customers. For instance, one can expect that enterprise applications will then be developed by users, materializing mash-ups that are scripted in high-level mash-up languages [3]. Ideally, users and customers should be able to create and submit their own contents via an easy to use interface, that is available on demand and which knowledge objects will be reviewed in accordance with knowledge management principles, the content can then be validated, annotated, evaluated; ranked and made searchable either internally or externally (or both).

These new forms of collaboration and collective creation will post probably impact the nature and shape of established approaches to business intelligence and knowledge management projects within corporations. As an example, recent research indicates that such evolutions will enable a brand new type of super-application "enabling trade, exchange and monetizing of knowledge assets" [3] and to some extent decoupled, completely pluggable, smart KM applications able of adjustments and interface with knowledge clouds systems. The interaction with customers and feedback from knowledge consumers is therefore fully part of such an effort, and its analysis translates the capacity of the service provider to monitor its knowledge market.

\section{Conclusion and future research}

Despite the emerging research trend about cloud computing and knowledge management framework, current research lacks of studies introducing a whole knowledge management model. Mechanisms underlying knowledge management in the cloud and how the processing of relevant data can facilitate and optimize the delivery of knowledge through different channels have not been explored. We proposed in this paper to introduce a new framework for knowledge management in cloud computing environment, described its specificities, as well as operating principles, and investigated the role of knowledge analytics to drive the application of, and support this framework. in this perspective, the present paper contributes to enrich our understanding of knowledge management practices in cloud computing environment, by identifying K-analytics that enable to support the AKAAS (Actionable Knowledge As A Service) Framework. 
Expected benefits of applications of the framework provide hints for placing users needs at the center of knowledge management programs and appreciate the role of data analytics in order to identify and fulfill such needs. Additionally, and similarly to existing cloud paradigms, the AKAAS approach is expected to improve the efficiency of the access to the needed knowledge, the relevancy and timeliness of the knowledge products delivered. Furthermore, research also demonstrated that adopting a cloud-based knowledge service environment enables organizations to foster an open innovation environment, by supporting knowledge flows and thus reducing time and costs for products development [22]. Despite great expectations, it is however clear that, besides technological and infrastructure readiness, the success of such knowledge-based service approaches also require adequate organizational support on the provider's' side as well as internal and external diffusion capabilities. It is also necessary to identify potential pitfalls in the deployment of such models and impacts of service interruptions on the adoption of knowledge services, which is a limitation of the current research and therefore brings us to explore future research axis. As an example, further research should integrate risks of security in managing data and analytics as well as related risks of knowledge loss.

As a continuance of this research, which is a preliminary step towards the design, and implementation of the AKAAS paradigm, the proposed framework shall be assessed through a case study to refine its modalities and application in other contexts than customer service organizations. Alternative cloud-based knowledge systems designs (either for the inner enterprise or outside consumers) shall also be explored as regards their implementation and operation in different service markets, taking into account emerging social networking paradigms and theories. Ideally, this examination should also integrate insights from users of knowledge services to determine and illustrate whether its application are also beneficial in other organizational contexts.

Competing interests

The authors declare that they have no competing interests.

\section{Authors' contributions}

AD performed the literature review, analysis and framework development for this work, and also drafted the manuscript. DD worked with AD to develop the BI/K-Analytics section and focus on the overall cloud-computing landscape. All authors read and approved the final manuscript.

\section{Acknowledgements}

The authors are indebted to the faculty members of Telecom Ecole de Management / UEVE, as well as professors at the Institute for Knowledge and Innovation South-East Asia (IKIE-SEA) for their support and advises during research projects, as well as providing access to resources and infrastructures necessary to conduct such.

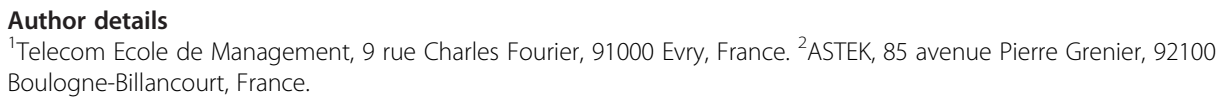

1. Rao Y, Lu S (2014) Service-Oriented Knowledge Acquisition Paradigm and Knowledge Cloud Platform. In: Wen Z, Li T (eds) Knowledge Engineering and Management, vol 278, Advances in Intelligent systems and Computing. Springer-Verlag, Berlin Heidelberg, pp 233-242

2. Rechberg I, Syed J (2014) Appropriation or participation of the individual in knowledge management. Manag Decis 52(3):426-445

3. Delic KA, Riley JA (2009) Enterprise Knowledge Clouds: Next Generation KM Systems? In: eKNOW., pp 49-53

4. Khoshnevis S, Rabeifar F (2012) Toward knowledge management as a service in cloud-based environments. Int J Mechatron Elec Computer Tech 2(4):88-110

5. Sultan N (2013) Knowledge management in the age of cloud computing and Web 2.0: Experiencing the power of disruptive innovations. Int J Inf Manag 33(1):160-165 
6. Sharif AM (2010) It's written in the cloud: the hype and promise of cloud computing. J Enterp Inf Manag 23(2):131-134

7. Low C, Chen Y, Wu M (2011) Understanding the determinants of cloud computing adoption. Ind Manag Data Systems 111(7):1006-1023

8. Terziyan V, Kaykova O (2012) From linked data and business intelligence to executable reality. Int J Adv Intelligent Sys 5(1-2):194-208

9. Dixon BE, Simonaitis L, Goldberg HS, Paterno MD, Schaeffer M, Hongsermeier T, Middleton B (2013) A pilot study of distributed knowledge management and clinical decision support in the cloud. Artif Intell Med 59(1):45-53

10. Géczy P, Izumi N, Hasida K (2012) Cloudsourcing: managing cloud adoption. Global J Business Res 6(2):57-70

11. Tsui E, Cheong R.K, Sabetzadeh F (2011) Cloud-based personal knowledge management as a service (PKMaaS). In: Computer Science and Service System, 2011. CSSS 2011. IEEE International Conference On. Nanjing, China, 27-29 June 2011, IEEE Vol.1 pp 2152-2155

12. Lai IK, Tam SK, Chan MF (2012) Knowledge cloud system for network collaboration: A case study in medical service industry in China. Expert Syst App 39(15):12205-12212

13. Rustam DD, Van der Weide TPT (2014). Towards a methodological framework for designing a knowledge market. In Advanced Informatics: Concept, Theory and Application, 2014. ICAICTA 2014. IEEE International Conference On. Bandung, 20-21 August 2014, IEEE Vol. 1 pp. 232-237

14. Dai W, Liu JJ, Korthaus A (2014) Dynamic on-demand solution delivery based on a context-aware services management framework. Int J Grid Utility Computing 5(1):33-49

15. Ju D, Shen B (2010) Knowledge Services for Knowledge Workers. In: Lytras MD et al (eds) Knowledge Management, Information Systems, E-Learning, and Sustainability Research. Springer-Verlag, Berlin Heidelberg, pp 51-59

16. Rahman FA, Desa Ml, Wibowo A, Haris NA (2014) Knowledge Discovery Database (KDD)-Data Mining Application in Transportation. Proc Elec Eng Computer Sci Informatics EECSI 2014:116-119

17. Herschel RT, Jones NE (2005) Knowledge management and business intelligence: the importance of integration. J Knowl Manag 9(4):45-55

18. Zuluaga GG, Sanin C, Szczerbicki E (2011) Smart Decision Infrastructure: Architecture Discussion. Cybernetics Sys Int J 42(2):139-155

19. Peng Y, Kou G, Shi Y, Chen Z (2008) A descriptive framework for the field of data mining and knowledge discovery. Int J Infor Tech Dec Making 7(4):639-682

20. Preda N, Kasneci G, Suchanek FM, Neumann T, Yuan W, Weikum G. (2010) Active knowledge: dynamically enriching RDF knowledge bases by web services. In: Proceedings of the 2010 ACM SIGMOD International Conference on Management of data. ACM New-York, NY, USA. pp 399-410

21. Venters W, Whitley EA (2012) A critical review of cloud computing: researching desires and realities. I Inf Technol 27(3):179-197

22. Zhang Z, Li X, Liu Y, Xie Y (2014) Distributed Resource Environment: A Cloud-Based Design Knowledge Service Paradigm. In: Schaefer D (ed) Cloud-Based Design and Manufacturing (CBDM), Springer International Publishing, Switzerland, Cham, pp 63-87

\section{Submit your manuscript to a SpringerOpen ${ }^{\circ}$} journal and benefit from:

- Convenient online submission

- Rigorous peer review

- Immediate publication on acceptance

- Open access: articles freely available online

- High visibility within the field

Retaining the copyright to your article 